\title{
O ORDENAMENTO COERCITIVO DE HANS KELSEN: UMA ANÁLISE (CRÍTICA) ACERCA DA CENTRALIDADE DA SANÇÃO
}

\author{
HANS KELSEN'S COERCITIVE ORDINANCE: AN ANALYSIS \\ (CRITICAL) ABOUT THE CENTRALITY OF SANCTION
}

Recebido em 16/10/2017

Aprovado em 27/12/2017

\author{
MARIA CÂNDIDA SIMON AZEVEDO NASCIMENTO1
}

\begin{abstract}
RESUMO: Estudar clássicos como a Teoria Pura do Direito de Hans Kelsen é de suma importância para entender, ao menos minimamente, a história do Direito e, a partir daí, buscarmos uma concepção mais sofisticada desse. A preocupação com a obra de Kelsen se dá principalmente pela necessidade se repensar os autores clássicos da teoria jurídica. $\mathrm{O}$ caráter coercitivo de um ordenamento jurídico encontra seu respaldo através da sanção, elemento central da estática jurídica kelseniana. Isto posto, o presente estudo objetiva estudar especialmente as concepções de estática jurídica propostas por Hans Kelsen, no tocante à centralidade da sanção, bem como as críticas de outros autores impostas a essa particularidade. Nesse sentido, questiona-se: em que medida o Direito pode ter a sanção como questão central da estática do ordenamento jurídico e quais são possíveis substituições para essa centralidade? Por certo é notória a existência de normas que estatuam sanções em qualquer ordenamento jurídico, mas trazer a sanção para o centro da estática do Direito é, de certa forma, um conceito insuficiente para explicar a complexidade de um ordenamento jurídico. Dessa forma, as teorias propostas por autores como Norberto Bobbio, Herbert Hart, assim como Pontes de Miranda, se mostram mais adequadas e menos radicais no tocante ao assunto estudado.
\end{abstract}

PALAVRAS-CHAVE: Direito. Ciência. Positivismo. Estática Jurídica. Sanção.

ABSTRACT: To study classics such as Hans Kelsen's Pure Theory of Law is of short importance to understand, at least minimally, the history and origin of Law. It isn't an outdated theory, but rather one of the most (if not more) important theory of law ever developed. The coercive character of a legal system finds its support through the sanction, central element of the kelseniana legal static. Thus, the present study aims to study, in particular, Hans Kelsen's conceptions of legal static, regarding the centrality of the sanction, as well as the criticisms of other authors imposed on this particularity. In this sense, it's questioned: what extent can the Law have samson as the central issue of the legal system and what are possible substitutions for this centrality? Of course, the existence of norms that establish sanctions in any legal system is notorious, but bring the samson to the center of the static of Law is, in a way, an insufficient concept to explain the complexity of a legal system. Thus, the theory proposed by authors such as Norberto Bobbio, Herbert Hart, as well as Pontes de Miranda, are more appropriate and less radical in relation to the subject studied.

KEYWORDS: Law. Science. Positivism. Legal Static. Sanction.

${ }^{1}$ Mestranda em Direito Público pela Universidade do Vale do Rio dos Sinos. Especialista em Direito e Processo do Trabalho pela Universidade do Vale do Rio dos Sinos (2015); Graduada em Direito pela Universidade do Vale do Rio dos Sinos (2012); Advogada. 


\section{INTRODUÇÃO}

A Teoria Pura do Direito de Hans Kelsen é um clássico da Teoria Geral do Direito que trouxe (e ainda traz) fortes influências desde o século XX. Estudar essa teoria, portanto, ainda é um passo fundamental para compreender a Ciência do Direito em especial na sua corrente positivista normativista.

O tema proposto para o presente estudo gira em torno da sanção no sistema jurídico kelseniano, uma vez que esta se mostra a questão fundante do momento estático do ordenamento jurídico para esse autor e sua análise de suma importância para compreendermos seu pensamento.

Assim sendo, o tema delimita-se com a análise da centralidade da sanção e dos elementos que a compõem, bem como suas principais críticas, na medida em que o ordenamento jurídico segundo a Teoria Pura possui peculiaridades que the possibilitam diversos questionamentos, dentre elas, está a centralidade da sanção para a estática jurídica. $\mathrm{O}$ presente estudo visa, assim, traçar um apanhado conceitual acerca da sanção e suas críticas, buscando vincula-la aos demais elementos do ordenamento jurídico, em especial aqueles desenvolvidos no capítulo da estática jurídica da obra acima declinada.

O estudo a ser realizado gira em torno da questão sobre em que medida o Direito pode ter a sanção como questão central da estática do ordenamento jurídico e quais são possíveis substituições para essa centralidade?

Isto posto, objetiva-se principalmente estudar as concepções de estática jurídica proposta por Hans Kelsen, no tocante à centralidade da sanção, bem como as críticas de outros autores impostas a essa particularidade. O estudo se dará em torno da sua obra de maior destaque: Teoria Pura do Direito, uma vez que esta é um apanhado de todos os seus estudos e espelha a sua proposta de ordenamento jurídico.

No segundo capítulo será realizada uma breve explanação acerca da teoria kelseniana, buscando uma análise mais geral do ordenamento jurídico para esse autor, assim como uma contextualização de sua obra e uma análise acerca do sentido da sanção.

O terceiro capítulo deste estudo será dedicado exclusivamente à análise do capítulo da estática jurídica da Teoria Pura do Direito de Kelsen, assim, visa demonstrar porque a sanção é importante para a obra do autor e como se dá sua relação com todas as demais normas 
jurídicas postas no ordenamento. Para esse capítulo, assim como para o capítulo anterior será utilizada principalmente a obra estudada, bem como alguns comentadores que são estudiosos da Teoria do Direito no Brasil.

Por fim, o quarto capítulo dedicar-se-á a análise crítica da centralidade da sanção no ordenamento jurídico, traçando três panoramas de autores diferentes: Norberto Bobbio, Herbert Hart e Pontes de Miranda, visando buscar respostas ao questionamento proposto. A escolha destes três autores se deu na medida em que suas teorias representam clássicos da teoria jurídica contemporânea. Com relação ao primeiro - Bobbio - este se torna importante na medida em que teve seu momento inicial a partir de uma evidente inspiração kelseninana; o segundo - Hart - partiu de influências dadas pelo normativismo jurídico de John Austin, tendo em vista que muitas de suas objeções se aplicam a ambos os autores; também com relação ao terceiro crítico - Pontes de Miranda - esse também se mostra de suma importância uma vez que teve momentos em sua obra que aproximou-se bastante do normativismo kelseninano, entretanto, continuou a refutá-lo ferrenhamente em seus escritos posteriores.

Salienta-se, desde já, que o objetivo não é estudar exaustivamente as três teorias dos autores críticos, mas tão somente delinear a ideia geral de cada uma delas, razão pela qual será traçado apenas um breve cenário sobre cada uma.

Por fim, o presente estudo se justifica na medida em que é importantíssimo para o estudo do Direito repensar obras clássicas como a aqui estudada, pois ao analisarmos a proposta de estática jurídica kelseniana, podemos observar que esta foi uma das principais estruturas jurídicas apresentadas pela Ciência do Direito.

\section{O ORDENAMENTO COERCITIVO DE HANS KELSEN: CONTEXTUALIZAÇÃO E ANÁLISE DO SENTIDO DA SANÇÃO}

Hans Kelsen foi um teórico do direito pertencente à linha de pensamento jusfilosófica chamada de positivismo jurídico, juntamente com outros autores conhecidos, como, por 
exemplo, Herbert Hart e Norberto Bobbio. Antes de partirmos para a análise da sanção propriamente, importante é trazer uma brevíssima contextualização da obra kelseniana.

Jurista e filósofo que influenciou demasiadamente a teoria do Direito do século XX em diante, ainda pode ser encontrado em diversos trabalhos acadêmicos e profissionais da atualidade. Sua Teoria Pura do Direito ${ }^{2}$, que, em verdade, traz um apanhado de seus escritos e suas conclusões, sofreu e sofre duras críticas no decorrer dos anos.

Deveras, a teoria kelseniana foi (e ainda é) considerada uma das matrizes epistemológicas da teoria jurídica, através da delimitação objetiva de uma Ciência do Direito. Sua pretensão foi exatamente formular uma teoria pura do Direito e não uma teoria do Direito puro, “[...] propõe a substituição dos dualismos jurídicos, considerando-os posturas idealistas, por um critério monista, como condição de produção das classificações teóricas do direito". (ROCHA, 1985, p. 47).

Kelsen inicia sua Teoria Pura do Direito já salientando qual é o objetivo da obra:

A Teoria Pura do Direito é uma teoria do Direito positivo - do Direito positivo em geral, não de uma ordem jurídica especial. É teoria geral do Direito, não interpretação de particulares normas jurídicas, nacionais ou internacionais. Contudo, fornece uma teoria da interpretação. (KELSEN, 2009, p. 1).

Expressa basicamente uma metodologia pura, isto é, totalmente apartada de influências externas ao seu objeto, ou seja, “[...] ao postular sua pureza de método, considera que o direito deve ser ciência autônoma e neutra". (ROCHA, 1985, p. 47). Desta feita, “[...] em Kelsen há uma cisão entre Direito e Ciência do Direito que irá determinar, de maneira crucial, seu conceito de interpretação". (STRECK, 2017, p. 17). Mas essa teoria tem como principal perspectiva a visão de sanção como o centro da estática do ordenamento jurídico e a ideia da ação ou omissão especificadas pela ordem jurídica como único fator responsável pelo que se considera Direito.

Muitos defendem que o positivismo normativista de Kelsen não têm mais o condão de suprir as necessidades da sociedade atual. Entretanto, como bem ressalta Warat (1982, p. 108),

Kelsen, atualmente, deve ser visto como formando parte do senso comum teórico dos juristas, ou, melhor dizendo, como a sua manifestação mais

2 “[...] a Teoria Pura representa uma síntese do pensamento de Kelsen e reflete em si o interesse gerado pelas angústias espistemológicas do autor". (KEGEL, 2013. p. 44). 
interessante. A Teoria Pura do Direito foi concebida como um sistema conceitual, destinado a fornecer tanto as normas metodológicas para a adequada produção do saber dogmático do direito, como as categorias gerais desse modelo de conhecimento.

Dentre os itens estudados no capítulo da estática jurídica da obra de Kelsen, a sanção é que tem maior destaque, em especial pela sua preponderância sobre os demais elementos e, também, pois foi o ponto mais criticado da teoria por outros autores.

A distinção da ordem jurídica de outras ordens sociais, segundo Kelsen (2009), é exatamente o seu poder coercitivo, ou seja, sua capacidade de impor uma coerção quando há a inobservância de uma conduta determinada pela ordem jurídica. Além disso, a interpretação segundo a qual o fim da pena (ou da execução) consiste na prevenção pela intimidação, também é uma intepretação possível.

Como cediço, a teoria em destaque sofreu (e sofre) duras críticas, tanto no tocante ao seu extremo apego à ordem das proposições jurídicas, ou seja, ao seu desinteresse para com a realidade fática da sociedade, uma vez que "Enquanto uma ciência das normas, ela tem como questão o significado objetivo das normas jurídicas" (NEUMANN, 2013, p. 49), quanto no que toca ao seu fascínio pela sanção como questão central no ordenamento jurídico.

Para o presente estudo, nesse primeiro momento, importa apenas a análise da centralidade da sanção, uma vez que a proposta é ressaltar algumas questões necessárias para uma apreciação do conceito de sanção na Teoria Pura do Direito. Antes de passarmos à análise da centralidade da sanção, bem como as críticas impostas à ela, imperioso se faz uma breve explanação acerca do que a sanção representa para Kelsen e porque ela é tão importante na teoria desse autor.

A matriz antropológica da teoria kelseniana tem suas raízes nas concepções de estado de Thomas Hobbes (2015, p. 117-118). Segundo Hobbes, enquanto os homens viverem sem um poder que possa intimidá-los, eles vivem nesse estado de guerra no qual cada homem se opõe ao outro, ou seja, no estado de guerra de todos contra todos. Explica ainda que a guerra não consiste tão somente na batalha em si, mas sim na constante vontade ou disposição para entrar em guerra ou estar em guerra.

Nesse sentido, Kelsen também possui essa visão hobbesiana de que o homem possui tendências egoístas de perseguir interesses próprios, razão pela qual precisa de limites que somente o Direito pode lhe impor através de normas que estabeleçam sanções e que tornem o 
seu desrespeito menos vantajoso do que o próprio agir conforme a norma. Além disso, a aplicação da sanção também exige a figura de um agente soberano, que, no caso, é o Estado, o qual possui o condão de pôr em prática o cumprimento das sanções impostas a indivíduos infratores.

Percebe-se que, "Ao considerar oportuno se comportar conforme o sentido da norma, no entanto, ele ainda continua manifestando seu caráter naturalmente egoísta". (COELHO, 1999, p. 45). Essa é a essência da diferença do Direito para outras ordens sociais, tais como a moral $^{3}$, uma vez que o Direito, ao contrário das demais, trará prejuízos ao descumprimento de suas normas.

Além da matriz hobbesiana, "Kelsen, a maneira de Kant, considera os 'dados brutos' do mundo carentes de significação, devendo estes serem ordenados e apreendidos pelo teórico em um sistema que fornece inteligibilidade a estes dados". (KEGEL, 1989, p. 41).

A partir disso, Kelsen traça uma linha entre o ser e o dever ser, uma vez que as tendências naturais de alguns homens não podem ser evitadas nem mesmo a partir da imposição de algumas normas que traçam condutas, razão pela qual ele vai defender que o Direito opera no nível do dever ser. Assim sendo, essas normas deverão estar ligadas a outras normas as quais somente serão cumpridas quando evidente a desvantagem em caso do seu descumprimento. "Isto significa que o fundamento de validade de uma norma não se encontra na ordem do ser, da verificação concreta da conduta prescrita pela norma, mas se encontra na ordem do dever-ser, do que deve ser verificado". (KEGEL, 1989, p. 94).

Isto posto, no tocante ao conceito de sanção, Kelsen (2009, p. 122) não buscou delinear um parâmetro, uma vez que disserta acerca da sanção em diversas oportunidades em seus trabalhos, não conceituando-a de forma definitiva, mas classifica-a como tendo um caráter coativo:

Na medida em que o mal que funciona como sanção - a pena no sentido mais amplo da palavra - deve ser aplicada contra a vontade do atingido e, em caso de resistência, através do recurso à força física, a sanção tem o caráter de um ato de coação". (2009, p. 28).

\footnotetext{
3 Segundo Dworkin (2014, p. 612-613), "As palavras 'direito' e 'moral' designam conjuntos de normas muito diferentes. Essas diferenças são profundas e importantes. O direito pertence a uma comunidade particular. A moral, não: consiste ela num conjunto de padrões ou normas que se impõem imperativamente a todos. $\mathrm{O}$ direito, pelo menos em sua maior parte, é feito pelos seres humanos por meio de diversos tipos de decisões e práticas contingentes. [...] A moral não é criada por ninguém (exceto, em algumas teorias, por um deus) e não depende de nenhuma decisão ou prática humana".
} 


\section{REVISTA ACADÊMICA

Assim, importa dizer que "O prêmio e o castigo podem compreender-se no conceito de sanção. No entanto, usualmente, designa-se por sanção somente a pena, isto é, a liberdade, a honra, valores econômicos - a aplicar como consequência de uma determinada conduta [...]”. (2009, p. 26). Como bem salienta Kelsen (2009, p. 125), "Não há mala in se, mas apenas mala prohibita", isto é, não existe o mal em si, mas apenas o que é proibido, uma vez que o mal ou o bem são interpretações morais que dependem de concepções internas de cada indivíduo. Esses estariam além das concepções da Ciência do Direito, pois o Direito, a partir de Kelsen, seria uma Ciência do dever ser que não possui interesse nas concepções de certo e errado, mas apenas de direito e não direito.

A norma, portanto, não possui qualquer juízo de valor, ela é apenas a norma estabelecida pelo ordenamento a partir de critérios extremamente formais e conforme outros critérios estabelecidos pelo próprio ordenamento, sempre em observância dos fundamentos estabelecidos pela norma fundamental ${ }^{4}$, que é uma norma pressuposta pelo ordenamento jurídico, da qual se retira a validade de todas as outras normas. Embora a norma fundamental também seja de grande importância para a teoria kelseniana, por limitações objetivas, não será objeto do presente estudo.

Em assim sendo, a sanção é, portanto, uma espécie de ato de coação, sendo que esse último não necessariamente possui o caráter sancionador, mas também pode ocorrer em virtude de outros atos, como bem salienta Kelsen, quando reconhece a possibilidade de existirem atos de coação que não têm o caráter de sanção, como, por exemplo, o internamento de um doente mental.

A coerção sempre estará presente no ordenamento jurídico, pois essa visa, essencialmente, submeter o indivíduo à aplicação da norma prevista, o que se dará independentemente da vontade do sujeito, podendo, inclusive, se valer de força física para tanto. Ainda que o indivíduo aceite a aplicação da sanção imposta, sem que seja necessário o uso da força, não há a perda do caráter coativo da norma, uma vez que a coação sempre estará

\footnotetext{
${ }^{4}$ Kelsen (2009, p. 217) explica que: “Como já notamos, a norma que representa o fundamento de validade de uma outra norma é, em face desta, uma norma superior. Mas a indagação do fundamento de validade de uma norma não pode, tal como a investigação da causa de um determinado efeito, perder-se no interminável. Tem de terminar numa norma que se pressupõe como a última e a mais elevada. Como norma mais elevada, ela tem de ser pressuposta, visto que não pode ser posta por uma autoridade, cuja competência teria de se fundar numa norma ainda mais elevada. A sua validade já não pode ser derivada de uma norma mais elevada, o fundamento da sua validade já não pode ser posto em questão. Uma tal norma, pressuposta como a mais elevada, será aqui designada como norma fundamental (Grundnorm)". (grifo do autor).
} 
presente para o caso de ser necessária. Como bem salienta Warat (1979, p. 36), “E precisamente a relação conduta-sanção permite compreender que tipo de ações deve omitir para não ser sujeito passivo de uma sanção".

Isto posto, feitas essas considerações acerca do sentido da sanção para Kelsen, importante salientar que efetivamente a sanção tem grande destaque na teoria estudada, pois para ele é ela que dá o sentido ao ordenamento jurídico e sem ela o Direito não seria uma ordem social distinta das demais. As críticas de outros autores à sanção segundo as concepções kelsenianas serão tratadas em capítulo próprio, uma vez que também representam importante estudo acerta desse instituto, bem como a fim de melhor aprofundar o objetivo do presente estudo, que é a análise da sanção segundo Kelsen.

A partir de então, podemos passar à análise da sua centralidade, que possui particularidades essenciais que lhe distinguem da interpretação de outros autores, também positivistas, e que dá uma visão geral do que é o ordenamento jurídico para Kelsen.

\section{ESTÁTICA JURÍDICA: A CENTRALIDADE DA SANÇÃO NO ORDENAMENTO}

O capítulo da estática jurídica da Teoria Pura do Direito inicia com a análise de que o ordenamento jurídico é uma ordem social coercitiva, que possui duas espécies, as sanções e as coações que não possuem o caráter de sanção. Entretanto, antes de aprofundarmos essa análise, importa ressaltar que, conforme Kelsen (2009, p. 80), dentro do ordenamento jurídico é possível distinguir uma teoria estática de uma teoria dinâmica5, sendo que "A primeira tem por objeto o Direito como um sistema de normas em vigor, o Direito no seu momento estático; a outra tem por objeto o processo jurídico em que o Direito é produzido e aplicado, o Direito no seu movimento".

\footnotetext{
${ }^{5}$ A dinâmica jurídica segundo Kelsen (2009, p. 219), que em que pese não ser objeto do presente estudo, merece uma explicação ainda que breve, está relacionada à validade das normas jurídicas postas no ordenamento: "Trata-se, portanto, de uma norma estabelecida por um ato de vontade. A sua validade só pode, em última análise, ser fundamentada através de uma norma pressuposta por força da qual nos devemos conduzir em harmonia com os comandos da autoridade que a estabelece ou em conformidade com as normas criadas através do costume. Esta norma apenas pode fornecer o fundamento de validade, não o conteúdo de validade das normas sobre ela fundadas. Estas formam um sistema dinâmico de normas. O princípio segundo o qual se opera a fundamentação da validade das normas deste sistema é um princípio dinâmico".
} 
Assim, o capítulo IV de sua Teoria Pura do Direito, Kelsen dedica ao que ele chama de estática jurídica, propondo um estudo de como o ordenamento jurídico se distingue de outras ordens sociais e de que forma a coerção tem um papel fundamental para esta ciência. Portanto, para fins deste trabalho, o ponto central a ser analisado é o capítulo da estática jurídica e a centralidade da sanção.

Consoante já referido, Kelsen (2009, p. 64) conceitua o ordenamento jurídico como uma ordem coercitiva, isto é, todas as regras postas no sistema giram em torno de normas de coerção. Salienta que poderão existir normas não coercitivas, mas estas apenas têm validade pois estão ligadas a normas de coerção, sendo que aquelas são denominadas de normas nãoautônomas, ou seja, são normas que "[...] não estatuam elas próprias um ato coercitivo e, por isso, não contenham uma prescrição mas antes confiram competência para a produção de normas ou contenham uma permissão positiva $[\ldots]$... ${ }^{6}$

Dito isso, importante referir que, para Kelsen (2009, p. 121), existem duas espécies de coerções, dentre elas, a que ele chama de sanções, aquelas ações ou omissões que estão prescritas pelo próprio ordenamento jurídico as quais a não observância acarreta uma coerção, como a prisão, por exemplo. Além disso, a outra espécie de coerção entendida seriam aquelas coações que não possuem caráter de sanção, mas que acarretam alguma restrição, como o internamento de um doente mental, embora o indivíduo não tenha praticado nenhuma ação ou omissão específica7.

Por sua vez, as sanções também são distinguidas em duas espécies, a pena, que seria a sanção penal, e a execução forçada, que corresponde à sanção civil. A pena é propriamente a realização compulsória de um mal, assim como a execução forçada, mas esta última distingue-se pelo fato de ser utilizada para indenizar o ilícito que a ação ou omissão de um indivíduo causou em prejuízo a um outro indivíduo. (KELSEN, 2009, p. 122).

\footnotetext{
${ }^{6}$ Apenas a fim de melhor compreendermos como é o pensamento kelseniano acerca da centralidade da sanção, importa ressaltar que para Kelsen $(2009$, p. 64): "Do que fica dito resulta que uma ordem jurídica, se bem que nem todas as suas normas estatuam atos de coação, pode, no entanto, ser caracterizada como ordem de coação, na medida em que todas as suas normas que não estatuam elas próprias um ato coercitivo e, por isso, não contenham uma prescrição mas antes confiram competência para a produção de normas ou contenham uma permissão positiva, são normas não-autônomas, pois apenas têm validade em ligação com uma norma estatuidora de um ato de coerção".
}

7 “Distinguem-se destas sanções, como já notamos, apenas na medida em que estes atos de coerção não são ligados, como consequências, a uma determinada ação ou omissão de certo indivíduo, ação ou omissão socialmente indesejável e juridicamente fixada, porquanto o seu pressuposto não é um ato ilícito ou um delito juridicamente prefixado e cometido por um determinado indivíduo". (KELSEN, 2009, p. 44-45). 
É nesse sentido, portanto, que o Direito se distingue de outras ordens sociais, na medida em que pode utilizar um ato coativo para aplicar uma sanção determinada pelo próprio ordenamento, caso o indivíduo resista à aplicação da mesma. "Sob esta ótica, a sanção surge como elemento fundante da própria norma jurídica e portanto integra o momento estático do ordenamento jurídico, articulando em torno de si os demais conceitos expostos na Teoria Pura". (KEGEL, 2013, p. 63).

Esse é o ponto alto da teoria de Kelsen, que, em verdade consiste em uma troca de perspectiva acerca do que significava a sanção para os positivistas, tais como John Austin ${ }^{8}$, uma vez que, segundo Kelsen, as normas sancionadoras são consideradas as primordiais e o centro do ordenamento jurídico, e não aquelas normas que preveem o comportamento, como ocorria tradicionalmente. (MASSON, 2007, p. 107). Entretanto, igualmente, é esse ponto da teoria kelseniana um dos mais criticados por outros autores clássicos, tais como Norberto Bobbio $^{9}$ e Herbert Hart ${ }^{10}$.

Continuando sua análise acerca da ordem jurídica, ainda em seu movimento estático, Kelsen passa a dissertar sobre o que é, em verdade, o ilícito ou delito. Para a doutrina tradicional (ou a jurisprudência tradicional), o ilícito seria a negação do Direito, aquela conduta que está fora do Direito, por ser contrária a ela e, portanto, seria algo de imoral. ${ }^{11}$ Ao contrário, a partir da Ciência Pura do Direito, a imoralidade não importa para a ordem jurídica, mas importa tão somente aquilo que a própria ordem jurídica prevê como ação ou omissão.

\footnotetext{
8 Segundo Austin (2002, p. 37), "El daño que probablemente se aplicará en el caso de desobediencia de un mandato, o (si se usa una expresión equivalente) en el caso de transgresión de un deber, se llama generalmente sanción, o imposición coativa de la obediência; en otros términos, se dice que el mandato o el deber son sancionados o impuestos coactivamente por la posibilidad de sufrir um daño".
}

9 "Para dar conta da mudança significativa que a sociedade sofreu, Bobbio irá desenvolver uma nova teoria das sanções, mais adequada à função promocional do Direito: a teoria das sanções positivas. Para Bobbio, um dos problemas da teoria kelseniana centrava-se em que na sua concepção de sanção a principal característica residia no emprego da força física organizada". (KEGEL, 2013. p. 67).

10 “A principal crítica de Hart a Kelsen refere-se ao caráter coercitivo de um ordenamento jurídico. Para Hart, existe uma grande variedade de normas que não correspondem à estrutura normativa kelseniana. Esta, para Hart, seria mais adequada ao esquema do Direito penal, mas com raríssimas aplicações no Direito Civil. Deste modo, Hart distingue as normas segundo três critérios: em relação ao conteúdo das leis, a sua origem e ao se campo de aplicação". (KEGEL, 2013. p. 70).

11 Cumpre ressaltar que "Enquanto a ciência jurídica interpreta como um pressuposto (condição) do Direito o delito, representado no pensamento ingênuo pré-científico como negação do Direito, como não-Direito (ilícito), cumpre um processo análogo ao da teologia em face do problema da teodiceia, isto é, em face do problema no mal num mundo criado por um Deus totalmente bom e todo-poderoso". (KELSEN, 2009, p. 127). 
Não há qualquer interferência de outras ciências do saber, não importa mais as razões morais internas de cada indivíduo, até mesmo porque, como bem ressalta Kelsen, o que para um é uma conduta imoral, para outros pode não o ser. Portanto, pretendeu acabar com a discussão de o que é justo ou injusto e fundar o ordenamento jurídico nele mesmo e não em fatores externos. (KELSEN, 2009, p. 125).

É, portanto, dessa forma que o ilícito, no ordenamento jurídico kelseniano é pressuposto do Direito e não negação, pois ele em verdade é o que a norma diz que é e, assim, faz parte do ordenamento e não está fora dele. Isto é, na jurisprudência tradicional o ilícito correspondia à negativa do Direito, mas em Kelsen, invertidamente, o ilícito corresponde ao pressuposto do Direito. Ocorre, portanto, uma inversão do que é o ilícito, uma vez que, consoante já referido, não existe mala in se, mas apenas mala prohibiita, ou seja, não há o mal ou o bem, mas tão somente o certo e o errado, sempre de acordo com o que está estatuído pela ordem social jurídica. (KELSEN, 2009, p. 125). Assim sendo, "Um e o mesmo fato é, segundo uma ordem jurídica, um ilícito ou delito, por esta lhe ligar a uma sanção, e não o é segundo uma outra que não prevê tal consequência". (KELSEN, 2009, p. 125). Assim, percebe-se que no ordenamento jurídico kelseniano tudo gira em torno da coerção.

Aliado ao conceito de ilícito, surge o conceito de dever jurídico, que também está intimamente ligado à sanção. Quando há uma ação ou omissão determinada pela ordem jurídica o indivíduo tem o dever de agir conforme essa norma. Caso opte por proceder de forma oposta à conduta devida, esse indivíduo aplica a norma, na medida em que sempre existirá uma outra norma que liga uma sanção à conduta oposta. $\mathrm{O}$ dever jurídico, portanto, não está vinculado a juízos morais ou impulsos ínsitos ao homem, pois mesmo que assim não seja, o indivíduo está adstrito à norma.

Isto posto, se o indivíduo cumpre o dever, ele observa a norma, mas se o indivíduo viola o dever, ele aplica a norma, todas as categorias ocorrem dentro do Direito. “Juridicamente obrigado está o indivíduo que, através da sua conduta, pode cometer o ilícito, isto é, o delito, e, assim, pode provocar a sanção, a consequência do ilícito - o delinquente potencial; ou o que pode evitar a sanção pela conduta oposta”. (KELSEN, 2009, p. 130).

No mesmo sentido, mas de forma diversa, podemos observar o conceito de responsabilidade. Esta ligada ao conceito de dever jurídico, entretanto, não é necessariamente dirigida ao delinquente, ou seja, aquele que praticou a conduta oposta ao dever jurídico, mas 
pode, como é, ser dirigida a outro indivíduo responsável pela consequência do ilícito. Isto é, o indivíduo que praticou a conduta não é, ou pode não ser, o mesmo responsável pela sanção imposta. (KELSEN, 2009, p. 133).

Ainda, no que toca ao direito subjetivo, que, segundo a doutrina tradicional, vem antes do dever jurídico, ou seja, reconhece que há uma sobreposição do direito sobre o dever, Kelsen também pretendeu inovar e, mais uma vez dialogando com a sanção, definiu que, em verdade, o direito subjetivo nada mais é do que o direito posto no ordenamento jurídico, ou seja, é aquilo que o direito objetivo diz que é. ${ }^{12}$

Por conseguinte, direito subjetivo possui desdobramentos, isto é, ele pode ser o direito de um determinado sujeito. "Esta situação, designada como 'direito' ou 'pretensão' de um indivíduo, não é porém, outra coisa senão o dever do outro ou dos outros”. (KELSEN, 2009, p. 142). O sujeito nesta relação é apenas o obrigado, isto é, aquele indivíduo que pela sua conduta pode violar ou cumprir o dever. O indivíduo que tem o direito é apenas objeto da conduta. (KELSEN, 2009, p. 143). Direito subjetivo, é, neste caso, o simples direito reflexo do dever jurídico de um indivíduo. Além disso, é também o poder jurídico de um indivíduo fazer valer o não cumprimento de um dever jurídico, por meio de ação judicial; ou um direito político de intervir nas normas postas no ordenamento jurídico; ou o poder de reclamar a validade de leis já postas no ordenamento; por fim, é também a permissão positiva de uma autoridade. (KELSEN, 2009, p. 162).

Em consequência, podemos dizer que os direitos subjetivos são concebidos como um complexo de normas que lhes sobre cai, guardando estreita ligação com a sanção. Não é diferente a relação existente no que toca à pessoa física e a pessoa jurídica, uma vez que, também esses, Kelsen determina que correspondem a um emaranhado de normas jurídicas, individuais ou coletivas. ${ }^{13}$ Deveras, se são um complexo de normas, a sua relação com a

12 "Se se designa a relação do indivíduo, em face do qual uma determinada conduta é devida, com o indivíduo obrigado a essa conduta como 'direito', este direito é apenas um reflexo daquele dever. [...] Este conceito de um direito subjetivo que apenas é o simples reflexo de um dever jurídico, isto é, o conceito de um direito reflexo, pode, como conceito auxiliar, facilitar a representação da situação jurídica”. (KELSEN, 2009, p. 143).

13 Ressalta Kelsen (2009, p. 213) que: "Desta forma, supera-se aquela posição subjetivista em face do Direito a cujo serviço se encontra o conceito de direito em sentido subjetivo: aquela concepção forense ou advocacial que apenas considera o Direito do ponto de vista dos interesses das partes, isto é, aquela concepção que o visualiza tendo apenas em mira saber o que ele significa para o indivíduo, em que medida lhe aproveita, quer dizer, em que medida serve o seu interesse, ou o prejudica, isto é, o ameaça com um mal". 
sanção é decisiva para a sua conceituação, uma vez que esta (a sanção) é componente essencial da norma.

A análise da sanção para o ordenamento jurídico segundo Kelsen pode ser muito mais desdobrada, situando sua relação com outros institutos estudados no capítulo da estática jurídica, tais como a capacidade de exercício, a competência, a organicidade, a capacidade jurídica e a representação, assim como a relação jurídica, mas tais desdobramentos ultrapassam os limites propostos na presente reflexão. Assim sendo, no que toca ao objeto proposto, a centralidade da sanção, conclui-se que é notória a sua importância para Kelsen no ordenamento jurídico e como o autor coloca os demais institutos ao seu redor.

Entretanto, muitas foram as críticas a essa centralidade da sanção proposta por Kelsen, razão pela qual se mostra interessante (ou importante) apresentar algumas delas, como forma de proporcionar um estudo mais aprofundado dessa análise epistêmica, consoante de discorrerá no capítulo seguinte.

\section{CRÍTICAS À CENTRALIDADE DA SANÇÃO}

\subsection{INTROITO}

Dentre as críticas impostas à teoria kelseniana, o reducionismo seria uma delas ${ }^{14}$. Conforme já referido, Kelsen foi muito criticado por ter colocado a sanção no centro da estática do ordenamento jurídico, o que, segundo teóricos críticos, acaba por reduzir o Direito a um sistema de ameaças e exercício de poder, pois o Direito seria muito mais do que isso. Entretanto, para muitos a sanção seria mesmo muito mais do que apenas ameaça, seria uma forma de motivação para que o indivíduo cumpra a norma, uma vez que inexistindo a motivação, o indivíduo está de certa forma livre para agir de forma contrária. Em verdade, o indivíduo é livre para escolher se vai agir conforme a norma ou contrário a norma, mas ele

\footnotetext{
14 "Mas o autor contra-argumenta tais críticas, apresentando duas teses antireducionistas. A primeira delas baseia-se no fato de que o Direito não é mera força na medida em que se apresenta, tão somente, como um ordenamento que institui, regula e organiza o uso da força. O poder jurídico não é, destarte, um poder baseado na superioridade da força física, é um poder normativo que se baseia em legitimidade e autorização (dada por normas) para exercer atos de coerção que, exatamente pelas razões expostas acima, sujeitar-se-ão às regras, que o limitarão, regularão e controlarão". (MASSON, 2007, p. 145)
} 
sabe que se agir contrário a norma uma sanção lhe será imposta. Toma, assim, muito mais um caráter motivacional do que um exercício de poder estatal. (MASSON, 2007).

Diversas são as opiniões contrárias a essa concepção de ordenamento jurídico proposta por Kelsen, uma vez que se mostra insuficiente sob vários aspectos. Assim sendo, as críticas feitas à teoria kelseniana serão analisadas aqui com base em três autores, isto é, Norberto Bobbio, Herbert Hart e Pontes de Miranda. Os dois primeiros são críticos clássicos da sanção kelseniana, por isso não podem ser deixados de lado para fins dessa análise crítica, já Pontes de Miranda será também citado aqui uma vez que num primeiro momento possui uma matriz positivista comtiana, mas no final de sua obra passa a analisar o Direito de forma mais objetiva (normativista), a exemplo de Kelsen, apesar de ainda assim criticá-lo fortemente, em especial no tocante à sanção.

\subsection{NORBERTO BOBBIO E AS SANÇÕES POSITIVAS}

Bobbio parte da concepção de que "O surgimento do direito como conjunto de normas negativas assinalava a passagem do estado de natureza para o estado civil, isto é, de um estado continuamente ameaçado pela guerra universal para um estado de paz". (BOBBIO, 2007, p. 3). Assim sendo, parte do pressuposto de que deve existir uma análise do Direito a partir das necessidades das sociedades contemporâneas, com vistas a suprir a concepção anterior - kelseniana - e alcançar uma nova análise estrutural do Direito, em especial em razão do término do Estado liberal e das mutações sociais, que acabam criando novas formas de poder e de controle social.

Ressalta que, “[...] nas sociedades industriais modernas, à medida que o processo de industrialização avança, as tarefas do Estado aumentam em vez de diminuir [...]” (BOBBIO, 2007, p. 5), razão pela qual salienta que “O mundo jurídico nos apareceu até agora muito mais articulado e complexo do que aparece nas várias tentativas de redução a esta ou aquela fórmula [...]". (BOBBIO, 2001, p. 146). Partindo desse pressuposto conclui que cada vez mais se mostra importante a existência de regras de encorajamento, abandonando-se a ideia de ordenamento como protetor-repressivo e partindo para uma transformação da função do sistema normativo. (BOBBIO, 2007). 
Assim, em verdade, pretendeu aprofundar o conceito de sanção para o ordenamento jurídico, com vistas a melhor adequá-lo ao papel do Direito mais para o final do século XX, inovando e trazendo para a Ciência do Direito o papel das sanções positivas. Primeiramente, busca identificar um critério para reconhecimento das normas jurídicas, mas salienta que "Violação da norma e sanção como resposta à violação estão implicadas em todo sistema normativo. Trata-se de ver se existem tipos diversos de resposta e se eles nos permitem uma classificação satisfatória dos diversos ordenamentos normativos”. (BOBBIO, 2001, p. 154).

Reconhece que a noção de sanção é importantíssima para o ordenamento jurídico, uma vez que, para ele, embora a sanção que ele chama de organizada seja elemento distintivo do ordenamento jurídico, esta não necessariamente estará em todo ele, mas sim representará grande parte dele. (BOBBIO, 1997, p. 29).

Explica que as sanções positivas, ao contrário das negativas, visam premiar uma boa ação praticada pelo indivíduo, ao contrário da remissa retribuir o mal com o mal, parte do pressuposto de que se deve retribuir o bem com o bem. Destarte, relaciona que

[...] a partir do momento em que o Estado assume a tarefa não apenas de controlar o desenvolvimento econômico, mas também de dirigi-lo, o instrumento idôneo para essa função não é mais a norma reforçada por uma sanção negativa contra aqueles que a transgridem, mas a diretiva econômica, que, frequentemente, é reforçada por uma sanção positiva em favor daqueles que a ela se conformam, como ocorre, por exemplo, nas denominadas leis de incentivo, que começam a ser estudadas com atenção pelos juristas. (BOBBIO, 2007, p. 209).

Isto posto, para Bobbio a visão clássica kelseniana, no sentido de ver o Estado como mantenedor da ordem pública, onde o Direito tem a coação como sua principal qualidade, não era mais suficiente ante o surgimento do Estado promocional, mantendo uma estrutura aberta de seu sistema. Dito isso, passa-se à análise da crítica imposta por Herbert Hart à teoria kelseniana, crítico ferrenho da centralidade da sanção. 


\subsection{HERBERT HART E A CONCEPÇÃO DE REGRAS PRIMÁRIAS E SECUNDÁRIAS}

Hart traça um apanhado crítico à teoria kelseniana, justamente no tocante à sanção que estaria por trás de todas as normas postas no ordenamento jurídico, pois para ele a concepção de que o ordenamento jurídico é um ordenamento coercitivo aplica-se mais propriamente ao direito penal, mas muito pouco ao direito civil, por exemplo, o que descaracterizaria essa concepção. Além disso, Hart postula o lado positivo do Direito e estimula a crítica reducionista à Kelsen, que reduz o Direito a uma ordem negativa.

Hart (1994, p. 11), no início de seu livro O Conceito de Direito, refere que ele não refuta a ideia de que o ordenamento jurídico possa ter normas que estatuam sanções, isso é inevitável, mas atribui elas, quase que exclusivamente, ao direito penal, e salienta que a redução do Direito a este simples elemento em verdade é uma confusão, é uma distorção do Direito, mesmo se formos analisar o direito penal. Questiona: o que são regras? Então passa a descrever os inúmeros tipos de normas diferentes, como, por exemplo, para Hart existem regras que são estabelecidas pela legislação, outras por atos não intencionais, algumas são imperativas, outras prescrevem procedimentos, formalidades, algumas são indicativas, entre outras. ${ }^{15}$ Ressalta que "É óbvio que a previsibilidade do castigo é um aspecto importante das regras jurídicas; mas não é possível aceitar isto como uma descrição exaustiva do que se quer dizer com a afirmação de que uma regra social existe [...]”. (HART, 1994, p. 15).

Em assim sendo, Hart (1994, p. 29) define que as ordens baseadas em ameaças estariam mais ligadas a um direito penal do que qualquer outra coisa, razão pela qual colocalas no centro do ordenamento jurídico faria com que tivéssemos que alegar que as outras leis que também podem ser encontradas no ordenamento seriam uma variação complexa dessas leis sancionadoras. Isso está equivocado segundo o pensamento hartiano, uma vez que há tipos de direito que parecem extremamente divergentes desse baseado em ameaças. Destarte, ele conclui: "Se compararmos a diversidade dos diferentes tipos de leis, que se encontram num sistema moderno como o do Direito Inglês, com o modelo simples de ordens coercitivas [...], ocorre ao espírito uma grande quantidade de objecções”. (1994, p. 33).

\footnotetext{
15 Mas mesmo se não atendermos por ora a esta complexidade e considerarmos apenas a primeira espécie de regra (que é típica do direito criminal) encontraremos, mesmo entre autores contemporâneos, a maior divergência de pontos de vista quanto ao significado da asserção de que existe uma regra deste tipo imperativo simples. (HART, 1994, p. 13).
} 
Com efeito, passa a defender que o ordenamento jurídico é composto por dois tipos de regras, isto é, "Por força das regras de um tipo, que bem pode ser considerado o tipo básico ou primário, aos seres humanos é exigido que façam ou se abstenham de fazer certas ações, quer queiram ou não”. (HART, 1994, p. 91). Essa, portanto, é a definição das regras primárias segundo Hart. Já no tocante às demais regras:

As regras do outro tipo são em certo sentido parasitas ou secundárias em relação às primeiras: porque asseguram que os seres humanos possam criar, ou fazer ou dizer certas coisas, novas regras do tipo primário, extinguir ou modificar regras antigas, ou determinar de diferentes modos a sua incidência ou fiscalizar a sua aplicação. (HART, 1994, p. 91).

Além dessa crítica ao ordenamento jurídico kelseniano, Hart também refuta a norma fundamental, pois para ele [...] a regra de reconhecimento é uma prática concreta, não necessitando, portanto, pressuposição de sua validade”. (KEGEL, 2013, p. 73).

Face às considerações aduzidas, resta evidente porque Hart é um crítico ferrenho da teoria kelseniana, dissertando veementemente em sua obra os motivos pelos quais para ele a sanção não é e não pode ser considerada como sendo todo o ordenamento jurídico, mas tão somente é parte dele, mais especificamente na definição de normas primárias.

Assim sendo, passa-se a análise do último autor proposto para apresentar uma crítica a centralidade da sanção em Kelsen.

\subsection{PONTES DE MIRANDA E SEU SISTEMA DE CIÊNCIA POSITIVA DO DIREITO}

Pontes de Miranda foi jurista que representou forte influência na Ciência do Direito a partir do século XX no Brasil, em especial com a sua obra Sistema de Ciência Positiva, publicada em 1922. Nessa, Pontes demonstra fortes traços de influência do positivismo de Augusto Comte, que procura estudar a Ciência do Direito interligada às outras ciências. Assim, nesse primeiro momento, Pontes se afasta totalmente do positivismo normativista kelseniano. (ALDROVANDI; SIMIONI; ENGELMANN, 2015).

Ao contrário de Kelsen, Pontes defendia que o Direito deveria ser extraído da realidade fática da sociedade e não ser proveniente apenas do próprio Direito, uma vez que 
esse somente era fruto dos fatos decorrentes na sociedade. Ou seja, o Direito, ao almejar uma determinada lei, o faz de acordo com determinados fatos que ocorrem no seio da sociedade, os quais são escolhidos para serem juridicizados, em detrimento de outros, mas por escolha da própria sociedade a que estão inseridos. Para Pontes a ciência do Direito é uma ciência empírica. (PONTES DE MIRANDA, 2000).

$\mathrm{Na}$ segunda fase de seu pensamento, Pontes caminha para uma análise mais normativista do Direito. "Essa análise dogmática, no entanto, dá origem a um paradoxo: a divisão entre o mundo fático e o mundo jurídico, que é a base da Teoria do Fato Jurídico, é incompatível com a unidade da ciência defendida na primeira fase do pensamento de Pontes de Miranda". (ALDROVANDI; SIMIONI; ENGELMANN, 2015, p. 19). Assim sendo, há uma aproximação da teoria pontesiana com o normativismo antes negado, em especial no tocante a dimensão de ser e dever ser proposta por Kelsen. (ALDROVANDI; SIMIONI; ENGELMANN, 2015, p. 19).

Apesar de na segunda fase de seu pensamento ter voltado seus estudos para um positivismo mais normativista, convergente com o positivismo kelseniano, e publicado seu Tratado de Direito Privado (1954-1970), Pontes não abandona as críticas lançadas em Sistema de Ciência Positiva do Direito e confirma sua oposição ao positivismo de Kelsen, traçando duras críticas ao pensamento desse autor. (ALDROVANDI; SIMIONI; ENGELMANN, 2015).

As críticas impostas dizem respeito tanto à extrema separação da Ciência do Direito das demais ciências, uma vez que, para Pontes essa separação é absurda, pois "De modo nenhum se há de tolerar reduzir-se a Ciência do Direito à chamada teoria pura do direito, isto é, do direito possível. A Ciência do Direito é ciência como as outras, analisa os fatos, é ciência empírica [...]” (PONTES, 2000, p. 357), quanto no tocante à sanção como o centro do ordenamento jurídico.

Com relação à essa última, Pontes ressalta que "Quanto ao Direito ser coação, para resolver lutas de interesses, suscitadas pelo egoísmo humano, foi teoria que repelimos". (PONTES, 2000, p. 345). Para fundamentar tal conclusão disserta que:

A função do Direito é a conciliação dos interesses coletivos com os dos indivíduos. O altruísmo pode entrar em luta, [...]. As sanções jurídicas são objetivas. Há sanções subjetivas, como as sanções morais. Depois, insistimos em dizer que a característica do Direito não é a coação, mas a segurança, a 
garantia [...]. Como se poderia ver coação na regra jurídica que diz 'com tal idade começa a capacidade jurídica', ou 'com tal idade pode inscrever-se na escola'? À incidência das regras jurídicas não é necessária a coerção. Têm-se empregado as duas expressões ('coação' e 'coerção') como se a regra jurídica fosse sempre de sanção coercitiva. (PONTES, 2000, p. 345).

Assim sendo, resta evidente que Pontes refuta a ideia de sanção proposta por Kelsen, justamente no tocante a esta ser a principal característica do Direito para esse autor, pois, como acima ressaltado, o Direito teria mais uma característica garantivista do que sancionadora.

Em assim sendo, feita essa análise de três diferentes críticas impostas à teoria kelseniana, em especial no tocante à característica coercitiva do Direito para esse autor, resta conclusiva a insuficiência desse conceito para ser o centro do ordenamento jurídico. Melhor análise será apreciada nas considerações finais, a fim de realizar um melhor fechamento do presente estudo.

\section{CONCLUSÃO}

Consoante pudemos perceber no decorrer do presente estudo, a Teoria Pura do Direito foi de grande importância, em especial no momento em que foi proposta. Sofreu duras críticas, mas também influenciou fortemente o positivismo jurídico do século XX em diante.

No tocante à sanção, propriamente, que foi objeto principal do estudo, essa se mostrou de extrema importância na teoria kelseniana, uma vez que é elemento fundante para essa visão de ordenamento jurídico. A partir de alguns pontos do texto, pode-se perceber que o momento em que Kelsen desenvolveu sua teoria é fundamental para entendê-la, pois, como bem ressalta Bobbio, o Direito no Estado liberal se mostra muito mais repressivo do que a concepção mais atual de Estado impõe. Além disso, as matrizes kelsenianas, em especial aquela fundada em Hobbes também demonstra claramente o porquê o ordenamento para Kelsen é um ordenamento coercitivo fundado na sanção.

Ao analisarmos o terceiro capítulo, é notória a sua integração no momento estático do ordenamento jurídico e sua relação com os demais elementos desse momento, razão pela qual pode-se concluir que a sanção é elemento fundamental do ordenamento jurídico. 
Sendo a sanção o elemento mais importante da teoria estudada, é também a mais criticada. A partir das críticas expostas no capítulo quatro, pode-se, também, chegar próximo a uma resposta ao questionamento proposto no item introdutório da presente pesquisa.

Assim sendo, a conclusão mais certa que primeiramente pode-se chegar é de que sempre o ordenamento jurídico trará normas que estatuam sanções, isso não é negado por nenhum dos três autores que apresentaram críticas a Kelsen. Mas a questão controvertida é se a sanção pode ser considerada o centro da estática do ordenamento jurídico, resposta a qual todos os três seguiram para a negativa, uma vez que, embora concordem com a existência de normas sancionadoras, não concordam que estas seriam consideradas as mais importantes ou o centro do sistema, mas sim parte dele.

Isto posto, cada autor sugere uma alternativa à centralidade da sanção, ou seja, não há um consenso comum de que forma o ordenamento jurídico deve estar estruturado, mas sim, ao menos entre os três - Bobbio, Hart e Pontes -, há o consenso de que a sanção não é o centro do ordenamento.

Bobbio propõe as sanções positivas, o que, de certa forma, se aproxima mais com o modelo de ordenamento a que estamos acostumados atualmente, um exemplo de sanção positiva, poderia ser o instituto da delação premiada no direito penal. Hart, por sua vez, propõe a sua visão de ordenamento dividido entre regras primárias e secundárias, o que também está condizente com os parâmetros atuais, por exemplo, onde existem diferentes tipos de normas, muitas delas que não estatuem sanções ou não estão ligadas a normas que estatuam sanções. Por fim, também Pontes, no mesmo sentido dos demais autores, também sustenta que a sanção é apenas parte do ordenamento jurídico, mas propõe uma visão de ordenamento mais garantista do que sancionadora.

Dito isso, pode-se concluir que a sanção segundo Kelsen pode ter sido importante para a época em que foi proposta, mas se mostra, de certa forma, um conceito insuficiente para explicar a complexidade que um ordenamento jurídico. Não significa que as teorias dos autores que criticaram Kelsen também não apresentem deficiências, mas no tocante à sanção, estão um pouco mais perto da realidade, ao menos atual, da ordem social jurídica. 


\section{REFERÊNCIAS}

ALDROVANDI, Andréa; SIMIONI, Rafael Lazzarotto; ENGELMANN, Wilson. Traços positivistas das teorias de Pontes de Miranda: influências do positivismo sobre Sistema de Ciência Positiva do Direito e Tratado de Direito Privado - um percurso com várias matizes teóricas. Civilistica.com, Rio de Janeiro, a. 4, n. 2, 2015. Disponível em: <http:// civilistica.com/wp-content/uploads/2015/12/Aldrovandi-Siminoni-e-Endelmanncivilistica.com-a.4.n.2.20151.pdf $>$. Acesso em: 04 jul. 2017.

AUSTIN, John. El objeto de la jurisprudência. Traducción Juan Ramón de Páramo Argüelles. Madrid: Centro de Estudios Constitucionales, 2002.

BOBBIO, Norberto. Da estrutura à função: novos estudos de teoria do direito. Tradução Daniela Beccaccia Versiani. Barueri: Manole, 2007.

BOBBIO, Norberto. Teoria da norma jurídica. Tradução Fernando Pavan Baptista e Ariani Bueno Sudatti. Bauru: Edipro, 2001.

BOBBIO, Norberto. Teoria do ordenamento jurídico. Tradução Maria Celeste Cordeiro Leite dos Santos. 10. ed. Brasília: Universidade de Brasília, 1997.

COELHO, Fábio Ulhoa. Para entender Kelsen: prólogo de Tércio Sampaio Ferraz Jr. 3. ed. São Paulo: Max Limonad, 1999.

DWORKIN, Ronald. A raposa e o porco-espinho: justiça e valor. Tradução Marcelo Brandão Cipolla. São Paulo: WMF Martins Fontes, 2014.

HART, Herbert. O conceito de Direito. Tradução A. Ribeiro Mendes. 2. ed. Lisboa: Fundação Calouste Gulbenkian, 1994.

HOBBES, Thomas. Leviatã: ou matéria, forma e poder de um estado eclesiástico e civil. Tradução Daniel Moreira Miranda. São Paulo: Edipro, 2015.

KEGEL, Patrícia Luiza. Uma análise do conceito de sanção no sistema jurídico de Hans Kelsen. In: ROCHA, Leonel Severo. (Org.). Paradoxos da auto-observação: percursos da teoria jurídica contemporânea. 2. ed. rev. e atual. Ijuí: Unijuí, 2013. p. 43-79. (Coleção direito, política e cidadania, 29).

KEGEL, Patrícia Luiza. Uma análise do conceito de sanção no sistema jurídico de Hans Kelsen. 1989. 166 f. Dissertação (Mestrado em Ciências Humanas - Especialidade Direito) Centro de Ciências Jurídicas, Programa de Pós Graduação em Direito, Universidade Federal de Santa Catarina, Santa Catarina, 1989. Disponível em: $<$ https://repositorio.ufsc.br/xmlui/ bitstream/handle/123456789/106307/78967.pdf?sequence=1\&isAllowed=y $>$. Acesso em 12 jul. 2017.

KELSEN, Hans. Teoria pura do direito. Tradução João Baptista Machado. 8. ed. São Paulo: WMF Martins Fontes, 2009. 
MASSON, Nathalia Ferreira. O conceito de sanção na teoria analítica do Direito. 2007. 153 f. Dissertação (Mestrado em Direito) - Departamento de Direito, Programa de PósGradução em Direito, Pontifícia Universidade Católica do Rio de Janeiro, Rio de Janeiro, 2007. Disponível em: <http://livros01.livrosgratis.com.br/cp077277.pdf>. Acesso em: 09 jul. 2017.

PONTES DE MIRANDA, Francisco Cavalcanti. Sistema de ciência positiva do direito. Campinas: Bookseller, 2000. Tomo III.

ROCHA, Leonel Severo. A problemática jurídica: uma introdução transdisciplinar. Porto Alegre: Sérgio Antonio Fabris, 1985.

STRECK, Lenio Luiz. Dicionário de hermenêutica: quarenta temas fundamentais da teoria do direito à luz da crítica hermenêutica do Direito. Belo Horizonte: Casa do Direito, 2017. (Coleção de dicionários jurídicos).

WARAT, Luis Alberto. Mitos e teorias na interpretação da lei. Porto Alegre: Síntese, 1979.

WARAT, Luis Alberto. A partir de Kelsen. Seqüência: estudos jurídicos e políticos, Florianópolis, v. 3, n. 4, p. 107-115, 1982. Disponível em: <https://periodicos.ufsc.br/ index.php/sequencia/article/view/17159/15719>. Acesso em 20 jun. 2017. 